\title{
Numerical Simulation and Rapid Centrifugal Casting of Large Complex Thin-Walled Titanium Alloy Intermediate Casing Based on 3D Printed Pattern
}

\section{Shurong Li}

Northwest Rare Metal Materials Research Institute Ningxia Co. Ltd.

\section{Yingchun Wang}

Henan University of Technology

\section{Xiao Zhang}

Northwest Rare Metal Materials Research Institute Ningxia Co. Ltd.

\section{Quangang Xian}

Chinese Academy of Sciences

\section{Yanjie Zhao}

Shanghai Jiao Tong University

\section{Chengkang Qi}

Shanghai Jiao Tong University

\section{Zhihui Li}

Shanghai Jiao Tong University

Junhua Lai

Shanghai Jiao Tong University

Fei Li ( $\square$ lifei74@sjtu.edu.cn )

Shanghai Jiao Tong University

\section{Research Article}

Keywords: Investment casting, Titanium alloy, Intermediate casin, 3D printed pattern, Numerical simulation

Posted Date: August 26th, 2021

DOI: https://doi.org/10.21203/rs.3.rs-829543/v1

License: (c) (1) This work is licensed under a Creative Commons Attribution 4.0 International License. Read Full License 


\section{Abstract}

Titanium alloy intermediate casing is a typical large casting, with many thin-walled and complex structures. It is a high cost and time-consuming process in the trial stage to manufacturing the wax pattern of the intermediate casing by metal mold. Rapid investment casting based on 3D printed patterns is the development direction of casting technology which integrates digitization and intelligence. In this study, selective laser sintering (SLS) technology was used to realize the rapid prototyping of polystyrene pattern in the precision casting of intermediate casing. A numerical simulation method was used to predict the filling process, solidification and casting defects of the intermediate casing. The simulation results show that the gating system for the casting of intermediate casting was reasonable, the number and size of gating risers met the open design requirements, and a sequential solidification of the casting could be realized. The titanium alloy intermediate casing with excellent metallurgical quality and size accuracy CT7 was successfully produced using centrifugal rapid casting technology.

\section{Introduction}

Investment casting is one of the most important and effectively used methods to produce metal components with high dimensional accuracy, excellent surface finish, and complex shapes [1-4]. Since the 1950s, investment casting technology has been widely used for manufacturing complex components in aviation, aerospace, automobile, etc. Especially in aviation, most hot end components such as turbine blade, turbine rotor blisk, impeller, casing have been produced by this process [5-8]. The traditional investment casting includes wax pattern pressing and assembly, ceramic shell preparation, alloy melt pouring, and post-treatment [9-12].

Intermediate casing is one of the largest titanium alloy componets in an aero-engine, characterized by a large, thin-walled and complex structure. Such component is ususally manufactured by investment casting. Nevertheless, the process of design and manufacture of metal mold for wax pattern has to spend a lot of time and cost. The ever-changing 3D printing technology has brought new opportunities for the casting of complex structural parts [14-18], among which selective laser sintering (SLS) technology is the most prominent [14]. With polystyrene (PS) resin as raw material, the investment casting pattern with complex structure can be manufactured by SLS equipment. The low-temperature wax infiltration process can greatly improve the surface finish and strength of the pattern, thus replacing the traditional wax pattern for the investment casting of complex metal components. In recent years, with the great improvement of its precision control level and worktable size, SLS can be used for the preparation of investment casting investment shell of large complex thin-walled structural parts. Such as intermediate casing to remove the shell manufacturing and wax pattern pressing links and greatly shorten the manufacturing cycle and cost of the intermediate casing.

At present, gravity casting and centrifugal casting are usually used in the titanium casting industry [1921]. The flow velocity and superheat of the titanium alloy melt in the shell ceramic shell are the basic process factors that greatly influence the filling ability of the gravity casting titanium alloy melt. Due to 
the use of ceramic shell melting furnaces in the titanium casting industry, the improvement of metal superheat is limited, and the increase of molten metal head is limited, so gravity casting is only suitable for casting titanium alloy castings with a simple shape and large wall thickness. Because the solidification speed of titanium alloy is very fast in the pouring process, and the interaction between the titanium alloy melt and the shell ceramic shell [22-24], a large amount of gas appears in the casting forming process in the shrinkage of the casting. The advantage of centrifugal casting is that it can improve the filling ability of metal melt and compact the casting structure. At the same time, the gas and slag in the melt move to the inner cavity of the casting under the action of centrifugal force so that it can reduce the shrinkage cavity, porosity, slag inclusion, and other defects in the casting. It is suitable for large, complex thin-walled castings with shell wall thickness less than $4 \mathrm{~mm}$. Large titanium alloy castings easily produce metallurgical defects such as shrinkage porosity during centrifugal casting, directly related to the gating system and gating process. If the metallurgical defects of large titanium alloy castings are solved by trial and error, the time and cost will greatly increase. In recent 20 years, simulation technology in investment casting has greatly helped to shorten the casting time. Using ProCAST and other software to simulate the casting process can verify whether the setting of riser and pouring process parameters are reasonable to use the best investment casting process to produce qualified castings [8, 25-27].

The outer diameter of a certain type of titanium alloy intermediate casing developed in this paper is more than $1 \mathrm{~m}$, and its structure is very complex. Titanium alloy has the characteristics of high melting point, low casting superheat, and large shrinkage tendency. In the process of liquid forming, it is easy to have casting defects such as cold shut, under casting, and porosity, which significantly affect the service life of parts. At the same time, if the intermediate casing is trial produced for $3 \sim 4$ rounds, the appropriate casting process can be determined, which will greatly increase the development cycle and cost. Therefore, this paper prepared a PS investment shell for titanium alloy intermediate casing precision casting based on 3D printing technology; combined with the use of ProCAST software, the centrifugal casting process was simulated, and the casting process of titanium alloy intermediate casing was verified.

\section{Experimental And Numerical Methods}

\subsection{Geometric model, simulation parameters and gating- system}

The three-dimensional structure of titanium alloy intermediate casing is shown in Fig. 1. Its outline size is $\Phi 1191 \times 302 \mathrm{~mm}$, and the minimum wall thickness is $4.5 \mathrm{~mm}$. The intermediate casing consists of a typical three-ring structure of the inner, outer, and hollow struts. There are 12 struts connected between the inner and outer rings, the central plane of which is $30^{\circ}$. In addition, there are many installation bumps at different positions. These thick structures are mostly connected with the thin-wall area of the casting, which easily become isolated hot spots and dangerous locations for shrinkage defects. The physical properties of Ti6Al4V titanium alloy for the intermediate casing were calculated by JMatPro software and 
then imported into ProCAST software to simulate the pouring process. The nominal composition of Ti6Al4V titanium alloy is shown in Table 1 . The liquidus temperature of Ti-6Al-4V alloy is $1635-1674{ }^{\circ} \mathrm{C}$ and the solidus temperature is $1593-1615^{\circ} \mathrm{C}$.

Table 1

Nominal composition of Ti6Al4V titanium alloy(wt.\%)

\begin{tabular}{|llllllll|}
\hline Al & V & Fe & C & N & H & O & Ti \\
\hline $5.5-6.8$ & $3.5-4.5$ & $\leq 0.30$ & $\leq 0.10$ & $\leq 0.05$ & $\leq 0.015$ & $\leq 0.20$ & Bal. \\
\hline
\end{tabular}

In order to eliminate shrinkage and porous defects in the intermediate casing, a bottom pouring gating system was designed to examine the flow and solidification behavior of the intermediate casing during the centrifugal casting, as shown in Fig. 2. The characteristics of the bottom pouring system are as follows: alloy melt is injected from the gate cup, through the straight runner to the runner at the lower part of the shell, and then filled from the lower part to the upper part.

The accuracy of numerical simulation of the centrifugal casting process is greatly affected by setting boundary conditions and selecting the materials' thermal parameters. In this study, the shell pre-heating temperature was $980^{\circ} \mathrm{C}$, and the heat transfer coefficient between alloy melt and ceramic shell interface was $1000 \mathrm{~W} /\left(\mathrm{m}^{2} \cdot \mathrm{K}\right)$. The pouring velocity and temperature were $0.75 \mathrm{~m} / \mathrm{s}$ and $1700^{\circ} \mathrm{C}$, respectively. The clockwise rotation speed of the iron centrifugal disk on which the guide shell was set as150 rpm. The cooling condition was air-cooling. The shell thickness was $20 \mathrm{~mm} \pm 1 \mathrm{~mm}$, and the backup shell material was refractory mullite with a density of $3150 \mathrm{~kg} / \mathrm{m}^{3}$. The thermal properties of the mullite could be found in the database of ProCAST software. All the above thermos-physical property data will be used to simulate the pouring process of titanium alloy.

\subsection{Rapid prototyping of wax patterns}

Because of the large and complex structure of titanium alloy intermediate casing, it is a long period and high cost to make the wax pattern for casting by mold pressing. In this study, polystyrene (PS) resin was used as raw material, selective laser sintering (SLS) technology was used to prepare the investment casting pattern for intermediate casing casting, and wax infiltration was carried out to improve its strength and surface finish to meet the requirements of titanium alloy intermediate casing. The optimized process parameters for SLS intermediate casing investment pattern were: laser power $13 \mathrm{~W}$, scanning distance $0.1 \mathrm{~mm}$, scanning speed $2000 \mathrm{~mm} / \mathrm{s}$, thickness of PS resin powder $0.1 \mathrm{~mm}$, pre-heating temperature $93.5^{\circ} \mathrm{C}$, particle size distribution of PS resin powder $80-100 \mu \mathrm{m}$. Figure $3(\mathrm{a})$ and (b) show the microstructure and photo of the 3D printed PS pattern, respectively. The PS pattern of the intermediate casing with the gating system was then covered with multi-layer stucco ceramic shell by using yttrium oxide $\left(\mathrm{Y}_{2} \mathrm{O}_{3}\right)$ as face coat material. After removing the PS pattern in the flash furnace, the ceramic shell for investment casting was obtained.

\subsection{Experimental verification and casting characterization}


The titanium alloy intermediate casing casting was completed by water-cooled copper crucible vacuum induction melting/centrifugal pouring furnace. The pouring furnace consists of two parts: (1) The upper part is the melting area of titanium alloy, where the water-cooled copper crucible and tungsten induction coil are located; (2) The lower part is the pouring area of the casting, where the centrifugal turntable, shell and guide groove are located. The pouring process of titanium alloy melt is as follows: (1) after preheating the shell on the sintering furnace at $980^{\circ} \mathrm{C}$ for $8 \mathrm{~h}$ in air, the shell was transferred into the pouring furnace. (2) The Ti6Al4V alloy melt in a crucible was poured into the shell that had been fixed on a steel disc. The rotational velocity used in the vertical centrifugal casting was set as $140 \mathrm{r} / \mathrm{min}$, which could ensure a complete filling for the shell cavity. The rotational direction was anticlockwise. (3) The shell containing the titanium alloy melt was cooled to room temperature. (4) The shell was completely removed, and sand-blasting was carried out on the casting surface. The casted intermediate casing was photographed by a digital camera and then detected by using the X-ray method.

\section{Results And Discussion}

\subsection{Flow analysis under the centrifugal casting process}

For titanium alloy intermediate casting, due to its complex structure and thin wall thickness, the surface tension between liquid titanium alloy metal and shell cannot be ignored, and the filling flow state of alloy melt in the thin-walled complex cavity has changed significantly. The filling process of titanium alloy melt directly affects the solidification process of the casting, plays an important role in the microstructure and the final quality of the casting, and then affects its performance. Therefore, it is of great guiding significance to explore the filling flow law of alloy melt in the thin-walled complex cavity for the actual production and microstructure as well as property control of titanium alloy complex castings. In this study, the filling order of the intermediate casing was firstly simulated, and the results are shown in Fig. 4. From Fig. 4 (a), it can be seen that the alloy melt flowed from the vertical runner under the gate cup to the bottom of the gating system and then through the 12 inner runners to the casting body. Subsequently, the alloy melt flowed down from the middle sprue diffuses smoothly to all gating system directions and began to fill from the bottom to top of the shell, as shown in Fig. 4 (b). When the filling time was up to $2.96 \mathrm{sec}$, as shown in Fig. 4 (c), starting from the outer ring of the intermediate casing, the alloy melt was stably filled to the hollow support plates. When the filling time was up to $4.96 \mathrm{sec}$, as shown in Fig. 4 (d), the intermediate casing was filled completely and local solidification occurred.

The velocity fields of the alloy melt could directly reflect the shell filling behavior of castings during the pouring process. Under the gravity pouring condition, the intermediate casing cannot be filled completely by titanium alloy melt due to the easy solidification property of titanium alloy melt and the large thinwalled structure of the intermediate casing. In the dual role of centrifugal and gravity forces, the shell filling became easily, which could be seen from the velocity field distribution of alloy melt in the process of filling simulation, as shown in Fig. 5. It can be seen from Fig. 5 (a) that the velocity of alloy melt was higher when it just contacted the bottom pouring runners, which was greater than $3 \mathrm{~m} \mathrm{~s}^{-1}$. As shown in 
Fig. 5 (b), the front flow velocity increased rapidly to $10 \mathrm{~m} \mathrm{~s}^{-1}$ under the centrifugal force when the alloy melt entered the casting body area through the gate. With the progress of the shell filling process, as shown in Fig. 5 (c and d), the alloy melt flowed through the thin-walled areas such as runner and hollow support plates, and the front velocity was decreased to about $8 \mathrm{~m} \mathrm{~s}^{-1}$, but still ensure the rapid and complete forming of the thin-walled area. In the whole filling process, the alloy melt filled the whole casting cavity from bottom to top through the bottom pouring runners and gate, and the flow process was stable and smooth without splashing and obvious turbulence. The above simulation results show that the design of the existing gating system is reasonable; the number and size of gating risers meet the open design requirements and can ensure that the casting surface has no obvious flow marks and cold shut defects.

\subsection{Solidification analysis}

The changes of solid fraction during the solidification process of the intermediate casing under the condition of centrifugal casting are shown in Fig. 6, in which the color bar represents the solid-phase fraction. " 0 " indicates the complete liquid and in contrast, " 1 " indicates the complete solid phase. As shown from Fig. 6 (a), when the alloy melt filling was completed, the cooling speed of the casting edge parts such as the outer ends of hollow struts was fast and rapid solidification occurred. With further cooling, as shown in Fig. 6 (b), the large upper part and hollow struts solidified rapidly due to the thin wall thickness, while the cooling speed of the upper and lower flanges and outer skeleton ring was slow due to the large structural thickness. The simulation results show that the solidification sequence of the casting and gating system was generally: outer ends of hollow struts $\rightarrow$ upper large thin-walled plate $\rightarrow$ upper flange $\rightarrow$ risers $\rightarrow$ lower flange $\rightarrow$ gate $\rightarrow$ bottom pouring runners $\rightarrow$ sprue. The solidification speed of the flange structure of the outer and inner rings of the casting was faster than that of the gate or riser connected with it to realize the sequential solidification of the casting, making the pouring system have enough liquid metal to feed the flange. However, there were still isolated hot spots at the inner ring flange and local installation boss structure, which might lead to shrinkage cavity and impact the casting quality.

Figure 7 shows the distribution of solidification time in the centrifugal casting process. It can be seen from Fig. 7 (a) that the solidification of hollow struts and upper large thin-walled plate of the intermediate casing was completed in tens of seconds. Further information can be seen from Fig. 7 (b): in areas near the flanges, gate, runners, and sprue, the solidification time gradually increased to hundreds of seconds, which indicates that the gating system of the intermediate casing could form a reasonable solidification time gradient distribution from sprue to casting body, which was conducive to the feeding of the alloy melt.

\section{3 casting defect analysis}

During centrifugal casting, the alloy melt fills the shell under the action of centrifugal pressure and extrudes the gas out of the shell, so that the casting has no holes and compact structure. Figure 8 shows the porosity distribution of intermediate casing after centrifugal casting. As shown in Fig. 8 (a), there were no obvious shrinkage defects in the key parts of the casing, such as the inner ring flange, the outer ring 
flange, and the installation boss. Most of the shrinkage defects appeared in the runner and riser surface, and the size was small. Figure 8 (b) shows the sectional defect distribution of a single hollow strut. It can be seen from Fig. 8 (b) that the shrinkage defects of the casting only existed in the sprues, and there were no obvious shrinkage defects in the strut part. The above results indicate that the pouring system and pouring process used in this study could meet the defect control requirements of the intermediate casing. The shrinkage defects in the casing casting could be eliminated by hot isostatic pressing, which has little effect on the casting quality. In conclusion, casing castings with good metallurgical quality can be obtained by using the above casting process.

\subsection{Experimental verification}

Based on the above simulation results, the actual casting verification of titanium alloy intermediate casing was carried out. The investment shell with pouring system for titanium alloy intermediate casing was prepared based on an SLS pattern. The flash-firing furnace was pre-heated to $800{ }^{\circ} \mathrm{C}$, the shell with investment shell was put directly into the furnace. The PS resin was completely gasified and burned at $800{ }^{\circ} \mathrm{C}$ for $6 \mathrm{~h}$, and the shell was air-cooled to room temperature. The shell was washed with water, sealed the plastic hole, and the insulation cotton was wrapped. The shell was pre-heated to $980{ }^{\circ} \mathrm{C}$ for 24 $\mathrm{h}$ and then transferred to the vacuum coagulation furnace for centrifugal casting at $1650{ }^{\circ} \mathrm{C}$. The pouring weight was $400 \mathrm{~kg}$, the rotating speed of the centrifugal plate was $140 \mathrm{rpm}$, and the pouring time was less than $10 \mathrm{~s}$.

After pouring, the insulation cotton was removed to accelerate the solidification and cooling speed of the casting. Finally, the casting was cut, polished, welded, heat-treated, and hot isostatic pressed to obtain a titanium alloy intermediate casing. X-ray, fluorescence, and three-dimensional measurement, the metallurgical quality of titanium alloy intermediate casing prepared by combining 3D printing technology with investment casting technology was excellent, and the dimensional accuracy reached CT7 level. The time required to complete the above work was only one-third of the traditional investment casting process.

\section{Conclusions}

In the present study, a large thin-walled titanium alloy intermediate casing for an aero-engine was successfully developed by combining 3D printing and ProCAST simulation optimization. The main contributions of this paper are as follows:

(1) Due to the large size and complex structure of titanium alloy intermediate casing, it is a long period and high cost to make a wax pattern for casting by metal mold pressing. Therefore, a polystyrene (PS) resin pattern was directly manufactured by a selective laser sintering (SLS) technology and subsequent wax infiltration for the shell building of the intermediate casing. The rapid casting technology based on 3D printing of PS resin pattern proved to produce large thin-walled titanium alloy components effectively. 
(2) According to the structural characteristics of the intermediate casing, a bottom pouring gating system was designed to examine the flow and solidification behavior of the intermediate casing during the centrifugal casting. The simulation results show that the gating system was reasonable, the number and size of gating risers met the open design requirements, and a sequential solidification of the casting could be realized. Furthermore, most shrinkage porosities were found to distribute in the gating system, but not in the casting body.

(3) The actual pouring result shows that the intermediate casing could be completely filled by the alloy melt, and no visible misrun and shrinkage defects formed in the casting using the gating system in this study. Meanwhile, the predicted shrinkage porosity defects matched well with the X-ray test results, the metallurgical quality of titanium alloy intermediate casing prepared by combining 3D printing technology with investment casting technology was excellent, and the dimensional accuracy reached CT7 level. The time required to complete the above work was only one-third of the traditional investment casting process.

\section{Ethical Approval}

and Consent to Participate

Not applicable.

Consent to Publish

Not applicable.

\section{Declarations}

\section{Ethical Approval and Consent to Participate}

Not applicable.

\section{Consent to Publish}

Not applicable.

\section{Authors Contributions}

- Shurong Li: Writing- Original draft preparation

- Yingchun Wang: Methodology

- Xiao Zhang: Conceptualization

- Quangang Xian: Methodology

- Yanjie Zhao: Investigation

- Chengkang Qi: Writing- Reviewing and Editing 
- Zhihui Li: Investigation

- Junhua Lai: Data curation

- Fei Li: Supervision

All authors read and approved the final manuscript.

\section{Funding}

This study was supported in part by grants from the Opening Foundation of the National Key Laboratory of Rare Metal Specialty Materials (SKL2018K001), the National Science and Technology Major Project "Aero-engine and Gas Turbine" (2017-VII-0008-0102), the National Natural Science Foundation of China (52074183) and the National Natural Science Foundation of Ningxia 区2019AAC03283区.

\section{Competing Interests}

The authors declare that they have no competing interests.

\section{Availability of data and materials}

All data generated or analysed during this study are included in this published article.

\section{Acknowledgments}

We appreciated Dr. Yulong Li for providing the 3D model of the casting in the manuscript.

\section{References}

1. Pattnaik SR, Karunakar DB, Jha PK (2012) Developments in investment casting process - a review. J Mater Process Technol 212: 2332-2348.

2. Singh S, Singh R (2015) Precision investment casting: A state of art review and future trends. Proc IMechE Part B: J Eng Manuf 230: 2143-2164.

3. Tian GL, Bu K, Zhao DQ, Zhang YL, Qiu F, Zhang XD, Ren SJ (2018) A shrinkage prediction method of investment casting based on geometric parameters. Int J Adv Manuf Technol 96:1035-1044.

4. Liu CH, Jin S, Lai XM, He B, Li F (2015) Influence of complex structure on the shrinkage of part in investment casting process. Int J Adv Manuf Technol 77:1191-1203.

5. Liang XF, Zhao YT, Ma DX, Jia ZG, Meng XF (2017) Study on the preparation and microstructure of a single-crystal hollow turbine blade. Mater Manuf Process 32: 1887-1892.

6. Venkat Y, Choudary KR, Das DK, Pandey AK, Singh S (2021) Ceramic shell moulds for investment casting of low-pressure turbine rotor blisk. Ceram Int 47: 5663-5670.

7. Li F, Wang YC, Wang DH, Zhao YJ, Qi CK, Sun BD (2020) Comparison of various gating systems for investment casting of hydraulic retarder impeller with complex geometry. 235: 583-593. 
8. Tao P, Shao H, Ji ZJ, Nan H. Xu QY (2018) Numerical simulation for the investment casting process of a large-size titanium alloy thin-wall casing. Prog Nat Sci-Mater 28: 520-528.

9. Bonilla W, Masood SH, lovenitti P (2001) An investigation of wax patterns for accuracy improvement in investment cast parts. Int J Adv Manuf Technol 18: 348-356.

10. Pattnaik S (2017) An investigation on enhancing ceramic shell properties using naturally available additives. Int J Adv Manuf Technol 91:3061-3078.

11. Kuo JK, Huang PH, Lai HY, Wu WJ (2019) Design of casting systems for stainless steel exhaust manifold based on defective prediction model and experimental verification. Int J Adv Manuf Technol 100:529-540.

12. Pereira JC, Gil E, Solaberrieta L, Sebastián MS, Bilbao Y, Rodríguez PP (2020) Comparison of AlSi7Mg0.6 alloy obtained by selective laser melting and investment casting processes: Microstructure and mechanical properties in as-built/as-cast and heat-treated conditions. Mater Sci Eng A 778:139124.

13. Lee K, Blackburn S, Welch ST (2015) Adhesion tension force between mould and pattern wax in investment castings. J Mater Process Technol 225: 369-374.

14. Yang JS, Shi YS, Shen QW, Yan CZ (2009) Selective laser sintering of HIPS and investment casting technology. J Mater Process Tchnol 209: 1901-1908.

15. Li H, Chen J, Chandrashekhara K, Xu M, Lekakh SN, Richards VL (2015) Characterization and modeling of anisotropic SL pattern during investment casting process. Int J Adv Manuf Technol 80: 1933-1943.

16. Mohiuddin MV, Hussainy SF, Krishnaiah A, Laxminarayana P (2017) Experimental investigation to produce thin-walled sand casting using combination of casting simulation and additive manufacturing techniques. Int J Adv Manuf Technol 90: 3147-3157.

17. Wang DH, Dong AP, Zhu GL, Shu Da, Sun JY, Li F, Sun BD (2019) Rapid casting of complex impeller based on 3D printing wax pattern and simulation optimization. Int J Adv Manuf Technol 100: 26292635.

18. Wang JY, Sama SR, Lynch PC, Manogharan G (2019) Design and topology optimization of 3Dprinted wax patterns for rapid investment casting. Procedia Manuf 34: 683-694.

19. Shen X, Yin YJ, Xiao G, Ji XY, Zhou JX (2019) Physical simulation of fluid frontal motion morphology in filling process of titanium alloy vertical centrifugal casting. Procedia Manuf 37: 51-58.

20. Li CY, Wang HY, Wu SP, Xu L, Wang KF, Fu HZ (2010) Research on mould filling and solidification of titanium alloy in vertical centrifugal casting. Rare Metal Mater Eng 39: 388-392.

21. Watanabea K, Miyakawa O, Takada Y, Okuno O, Okabe T (2003) Casting behavior of titanium alloys in a centrifugal casting machine. Biomaterials 24: 1737-1743.

22. Cheng $X$, Yuan $C$, Blackburn S, Withey PA (2014) The study of the influence of binder systems in an $\mathrm{Y}_{2} \mathrm{O}_{3}-\mathrm{ZrO}_{2}$ facecoat material on the investment casting slurries and shells properties. $J$ Eur Ceram Soc 34 : 3061-3068. 
23. Cui RJ, Gao M, Zhang H, Gong SK (2010) Interactions between TiAl alloys and yttria refractory material in casting process. J Mater Process Technol 210: 1190-1196.

24. Cheng X, Sun XD, Yuan C, Green NR, Withey PA (2012) An investigation of a TiAlO based refractory slurry face coat system for the investment casting of TieAl alloys. Intermetallics 29: 61-69.

25. Kuo JK, Huang PH, Lai HY, Chen JR (2017) Optimal gating system design for investment casting of $17-4 \mathrm{PH}$ stainless steel enclosed impeller by numerical simulation and experimental verification. Int $J$ Adv Manuf Technol 92: 1093-1103.

26. Liu XJ, Hao ZJ, Huang M (2020) Optimization of vacuum counter-pressure casting process for an aluminum alloy casing using numerical simulation and defect recognition techniques. Int $\mathrm{J}$ Adv Manuf Technol 107: 2783-2795.

27. Yu JP, Wang DH, Li DY, Tang D, Zhu GL, Dong AP, Shu D, Peng YH (2019) Physical simulation of investment casting for GTD-222 Ni-based superalloy processed by controlled cooling rates. Int $\mathrm{J}$ Adv Manuf Technol 105: 3531-3542.

\section{Figures}

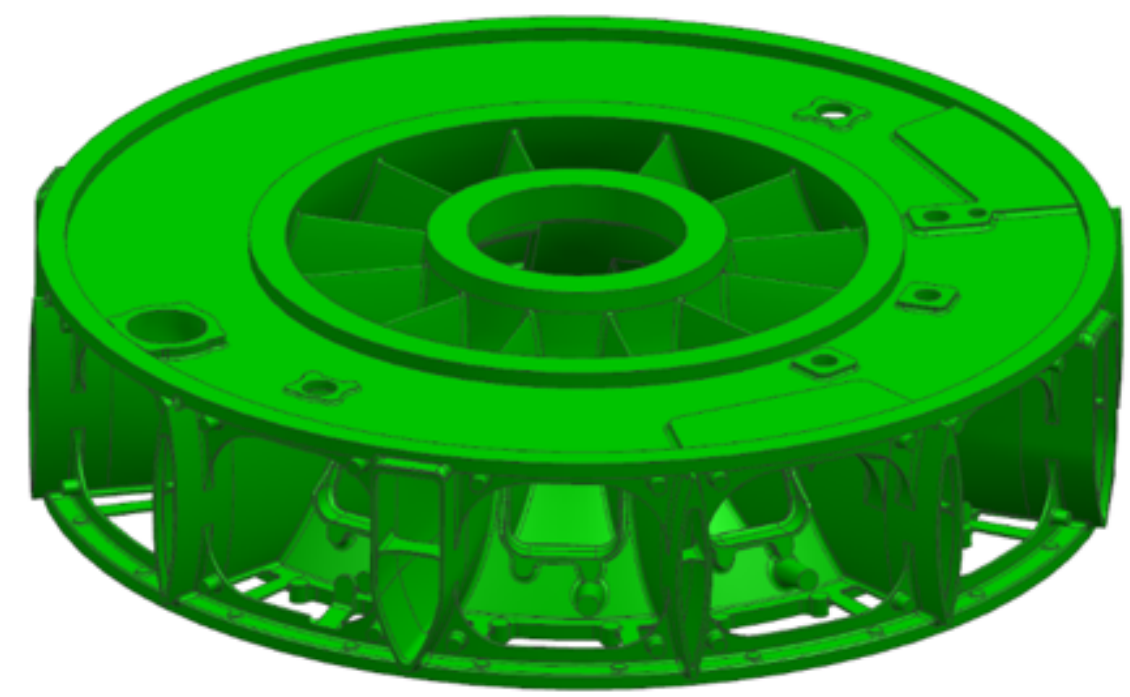

\section{Figure 1}

Three-dimensional structure of titanium alloy intermediate casing 


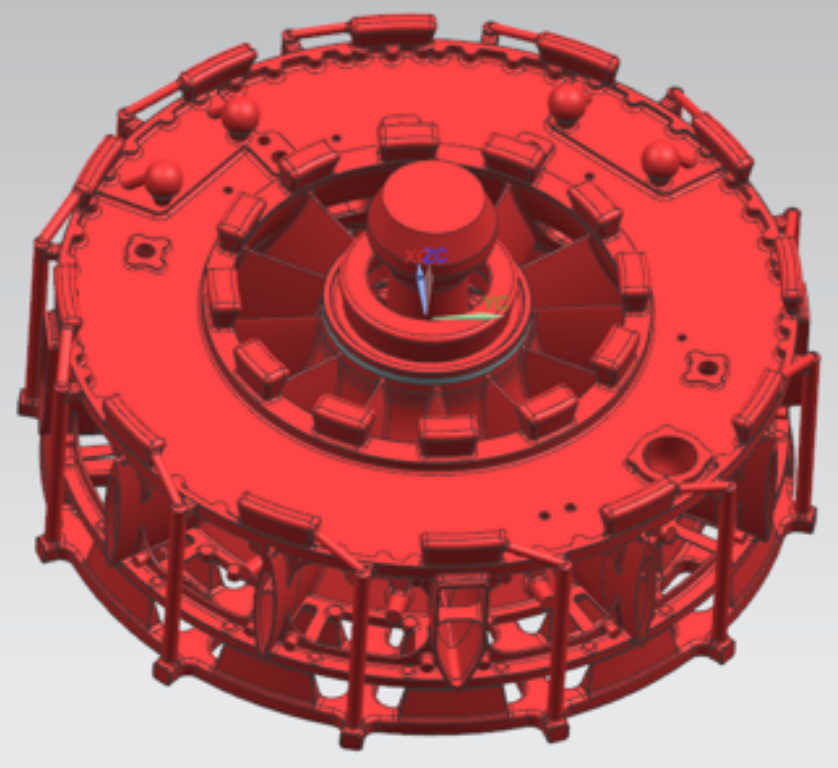

Figure 2

Gating system of titanium alloy intermediate casing 

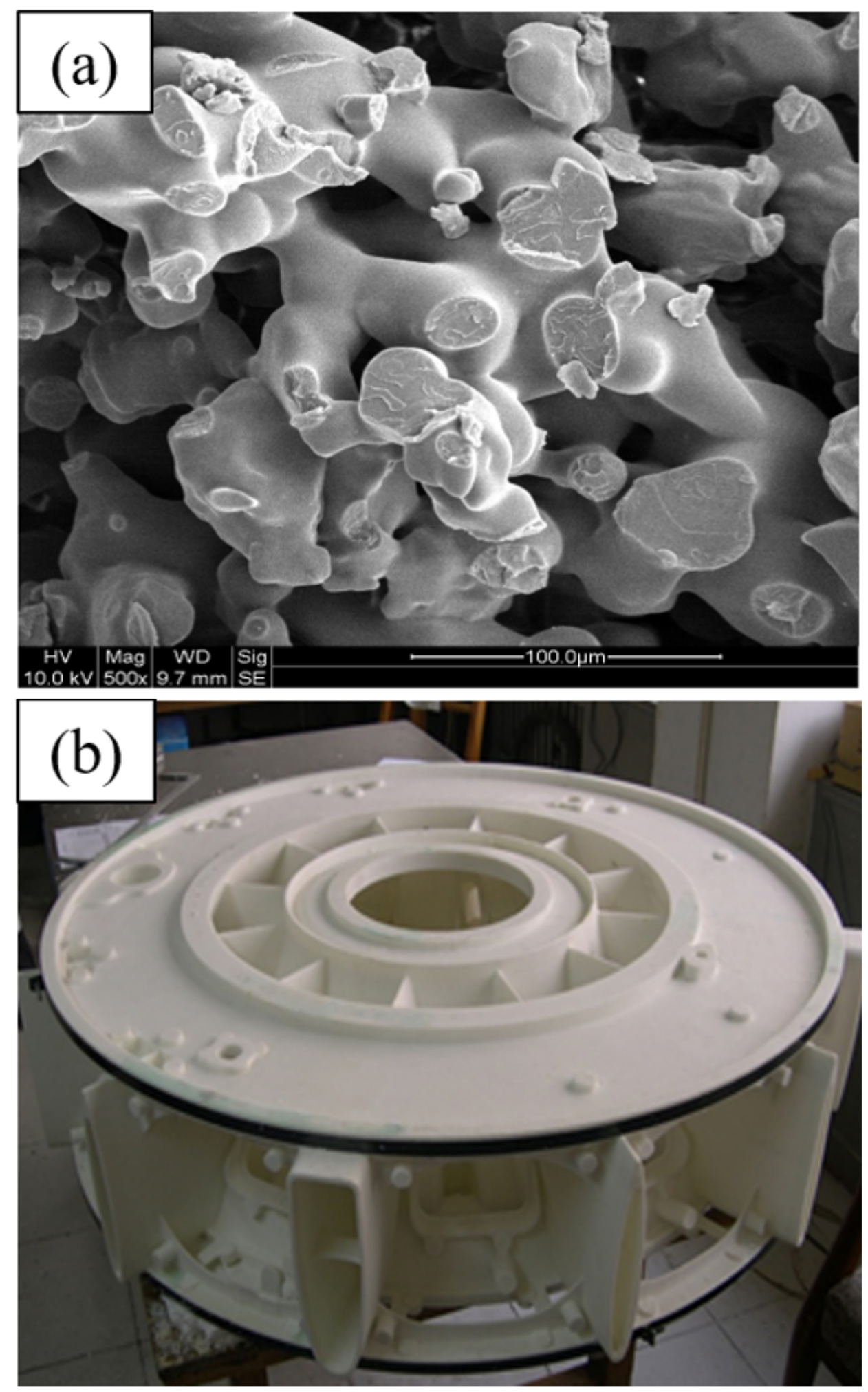

\section{Figure 3}

(a) microstructure and (b) photo of the 3D printed PS pattern of titanium alloy intermediate casing 


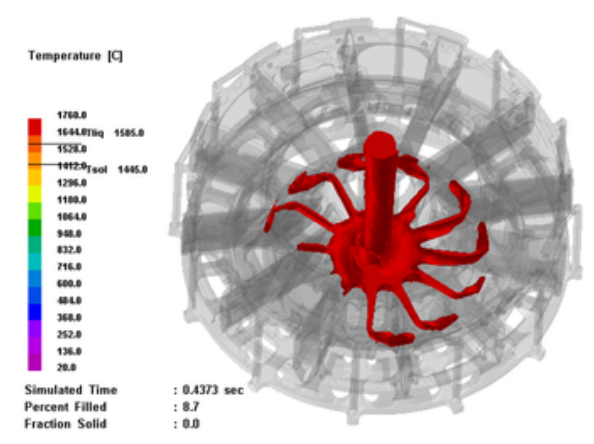

(a) $\mathrm{t}=0.44 \mathrm{~s}$

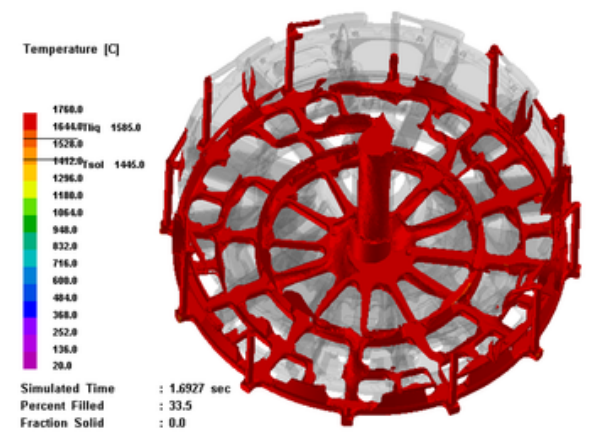

(b) t $=1.70 \mathrm{~s}$

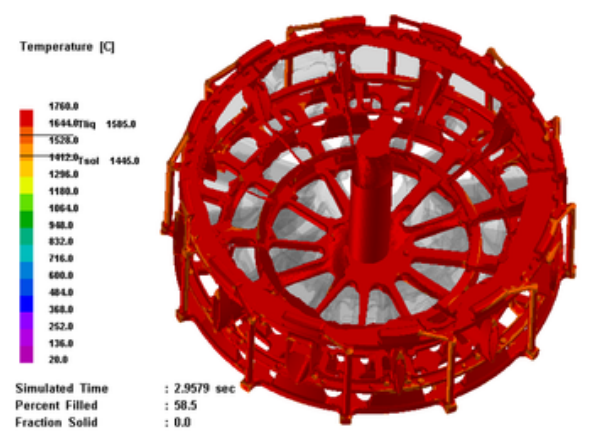

(c) $\mathrm{t}=2.96 \mathrm{~s}$

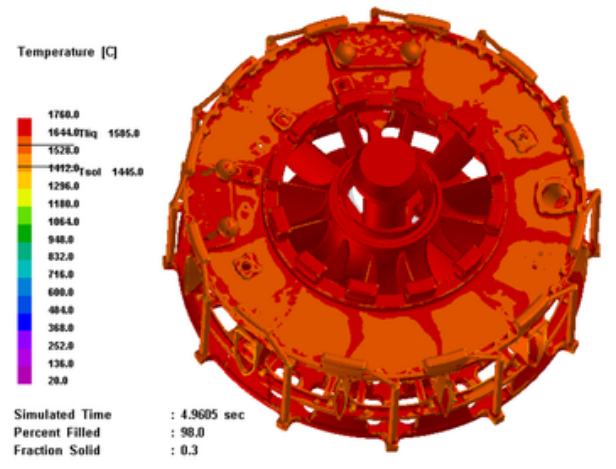

(d) $\mathrm{t}=4.96 \mathrm{~s}$

Figure 4

Filling order of titanium alloy melt in the shell during the pouring process of the intermediate casing 


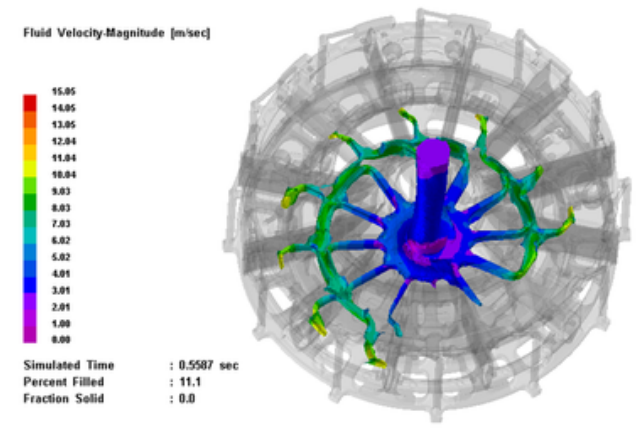

(a) t $=0.56 \mathrm{~s}$

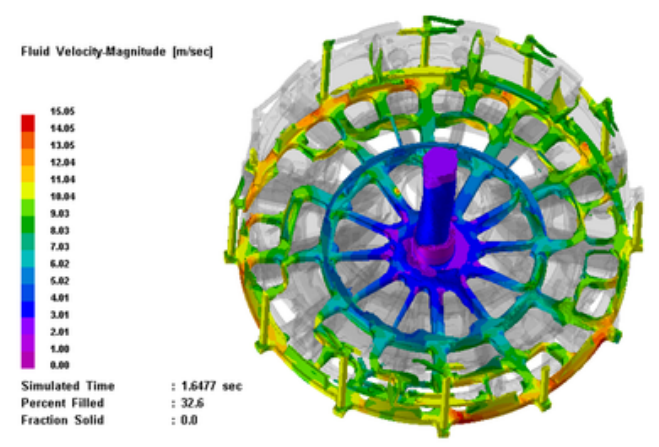

(b) $\mathrm{t}=1.65 \mathrm{~s}$

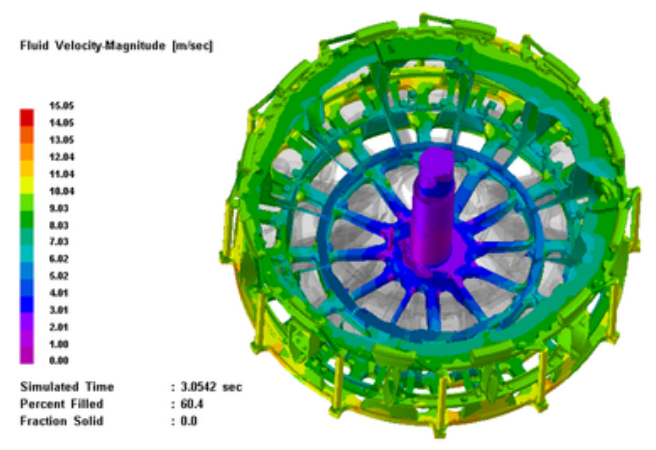

(c) $\mathrm{t}=3.05 \mathrm{~s}$

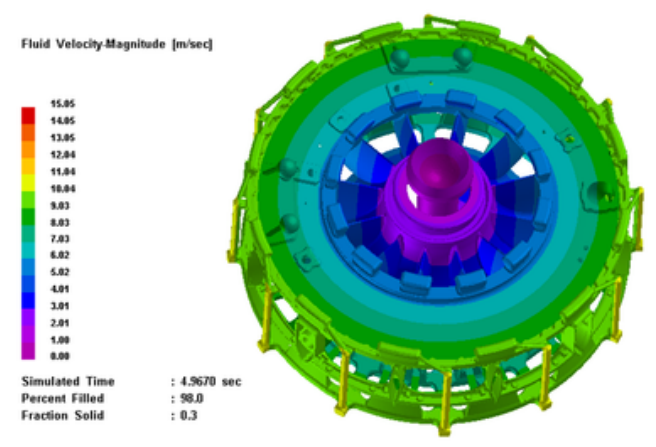

(d) $\mathrm{t}=4.97 \mathrm{~s}$

\section{Figure 5}

Velocity field distribution of metal liquid during the shell filling of titanium alloy intermediate casing at a different filling time (t: after pouring time) 


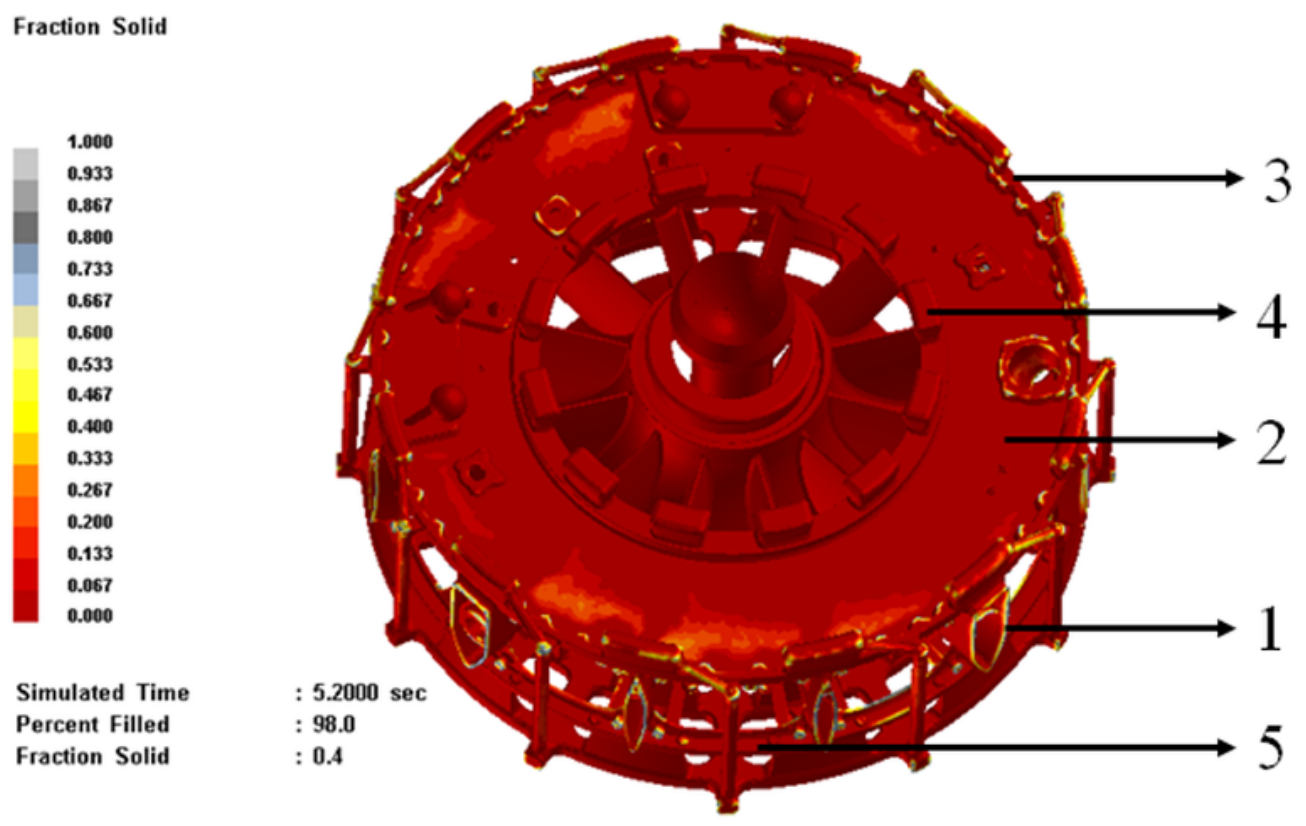

(a) Solid fraction: $0.4 \%$

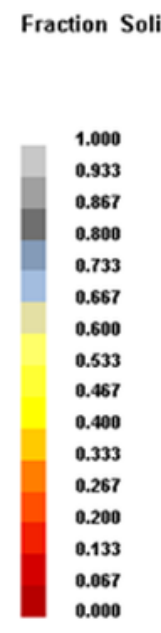

Simulated Time Percent Filled Fraction Solid

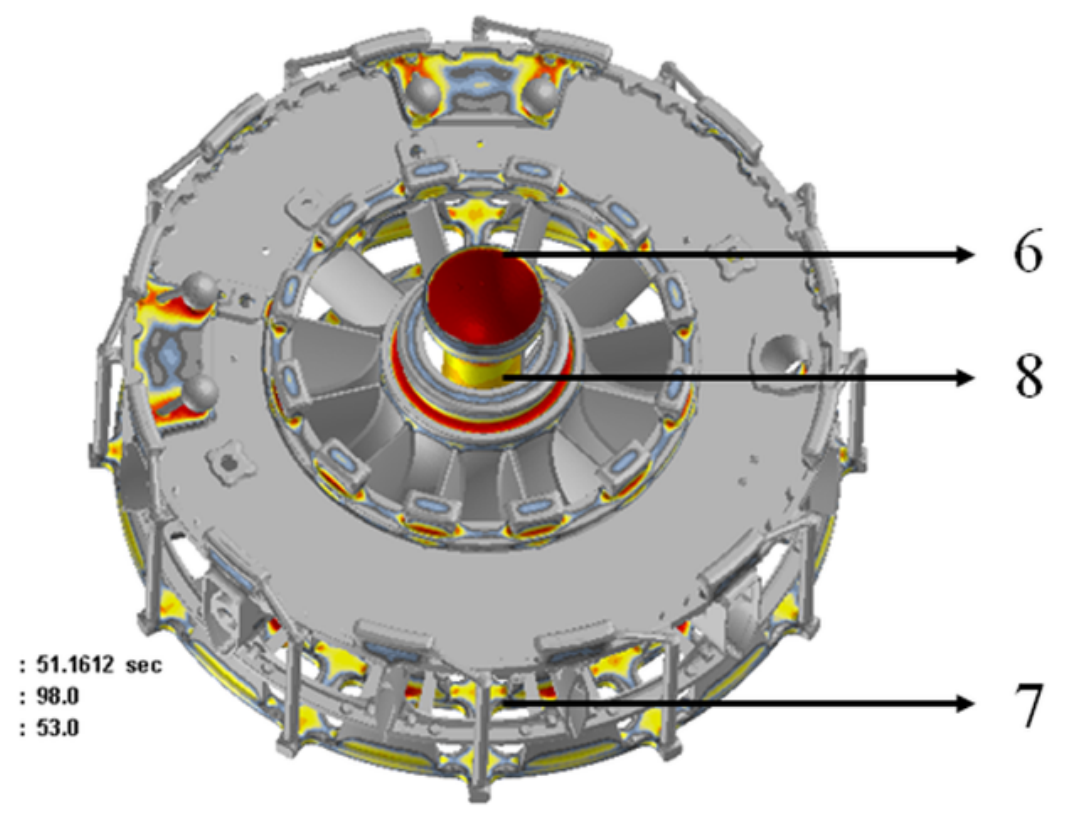

(b) Solid fraction: $53 \%$

\section{Figure 6}

Solid fraction of the intermediate casing in centrifugal casting 1- Outer ends of hollow struts, 2- upper large thin-walled plate, 3- upper flange, 4- risers, 5- lower flange, 6- gate, 7- bottom pouring runners, 8sprue 


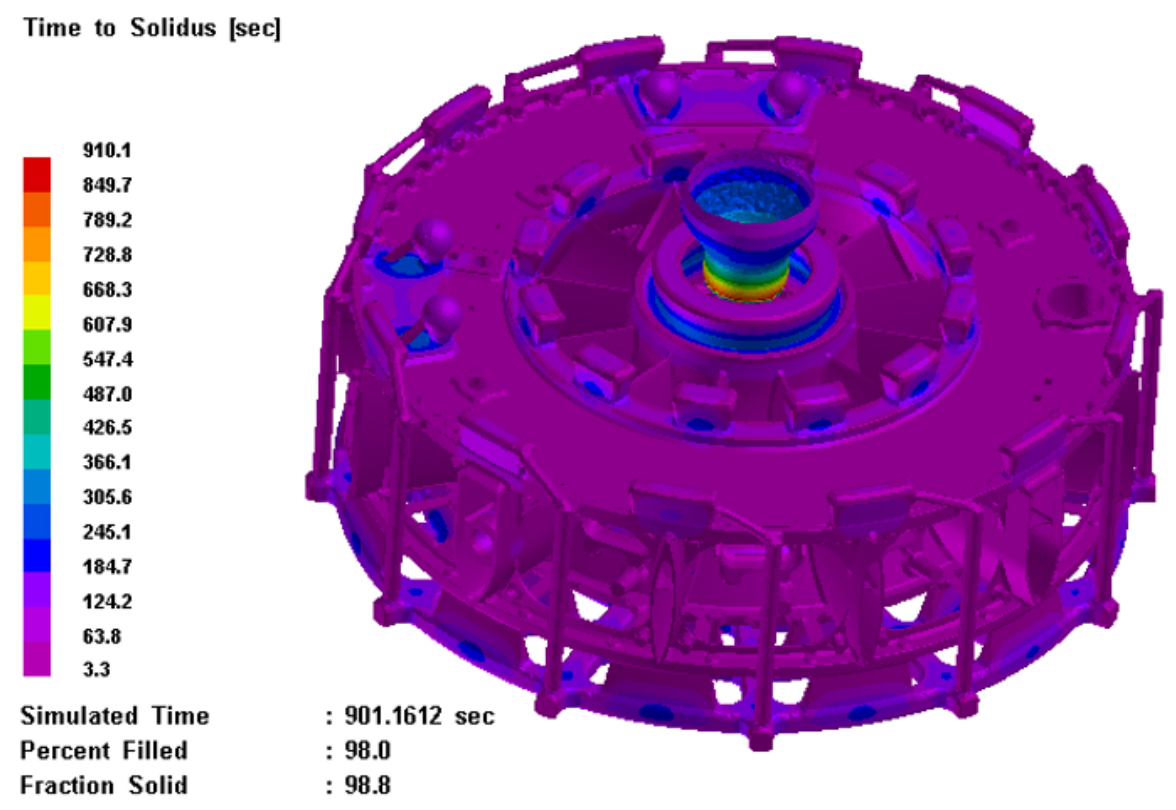

\section{(a) Integral casting}

Time to Solidus [sec]

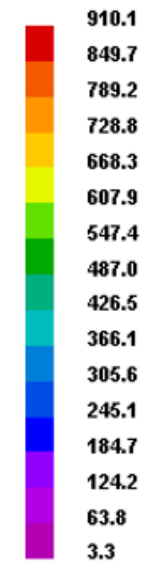

Simulated Time Percent Filled Fraction Solid

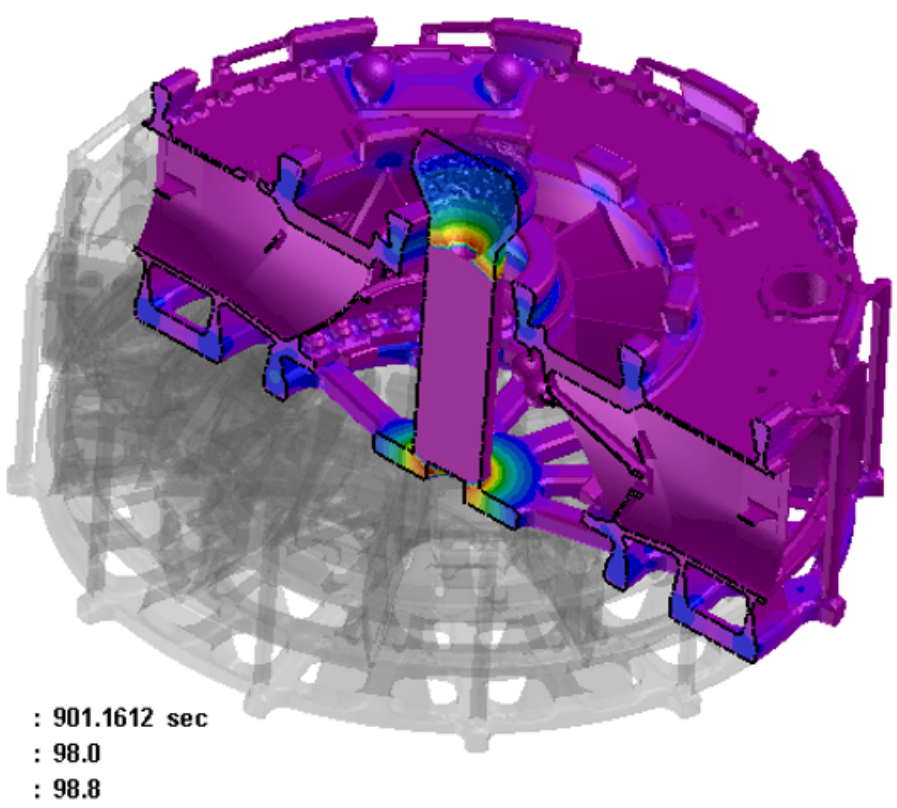

(b) Casting section

\section{Figure 7}

Distribution of solidification time in the investment casting process for the intermediate casing 
Shrinkage Porosity [\%]

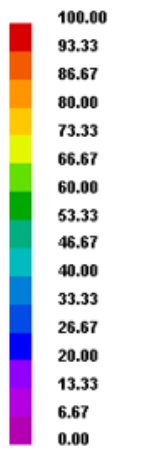

Simulated Time Percent Filled

Fraction Solid

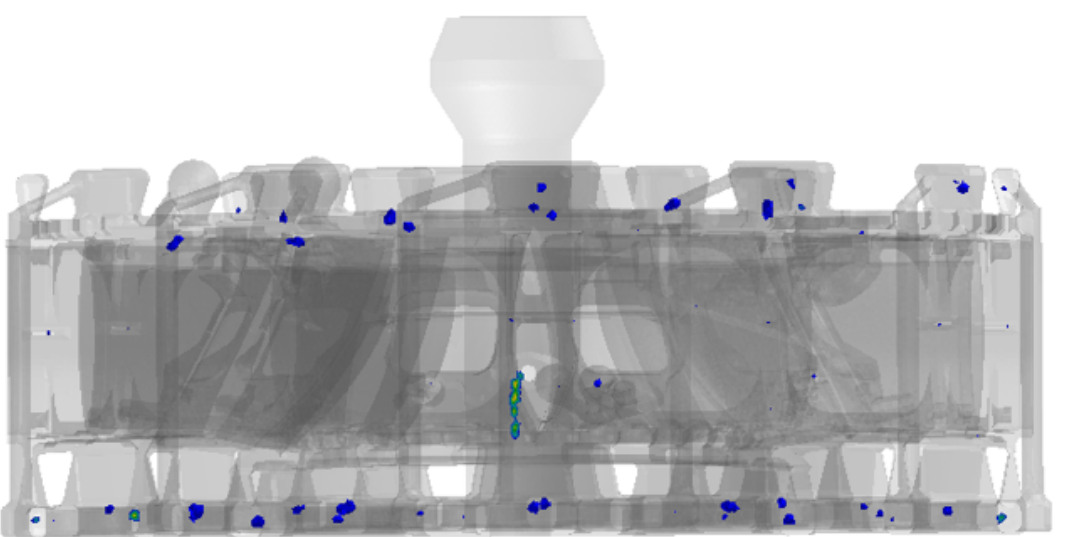

: $901.1612 \mathrm{sec}$

: 98.0

: 98.8

( a ) shrinkage defect distribution in the whole intermediate casing

Shrinkage Porosity $[\%]$

\begin{tabular}{|l|}
\hline 100.00 \\
93.33 \\
86.67 \\
80.00 \\
73.33 \\
66.67 \\
60.00 \\
53.33 \\
46.67 \\
40.00 \\
33.33 \\
26.67 \\
20.00 \\
13.33 \\
6.67 \\
0.00
\end{tabular}

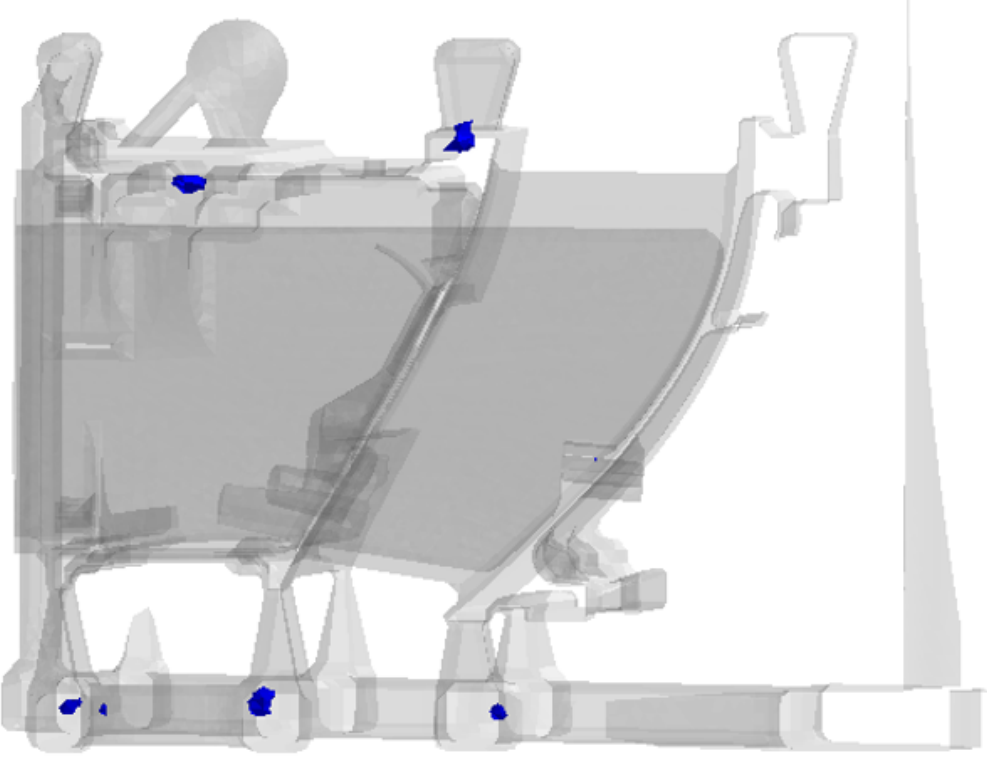

Simulated Time

: $901.1612 \mathrm{sec}$

Percent Filled

: 98.0

Fraction Solid

: 98.8

( b ) shrinkage defect distribution in a single hollow strut of the intermediate casing

Figure 8

Distribution of shrinkage defects in the intermediate casing of titanium alloy after solidification 


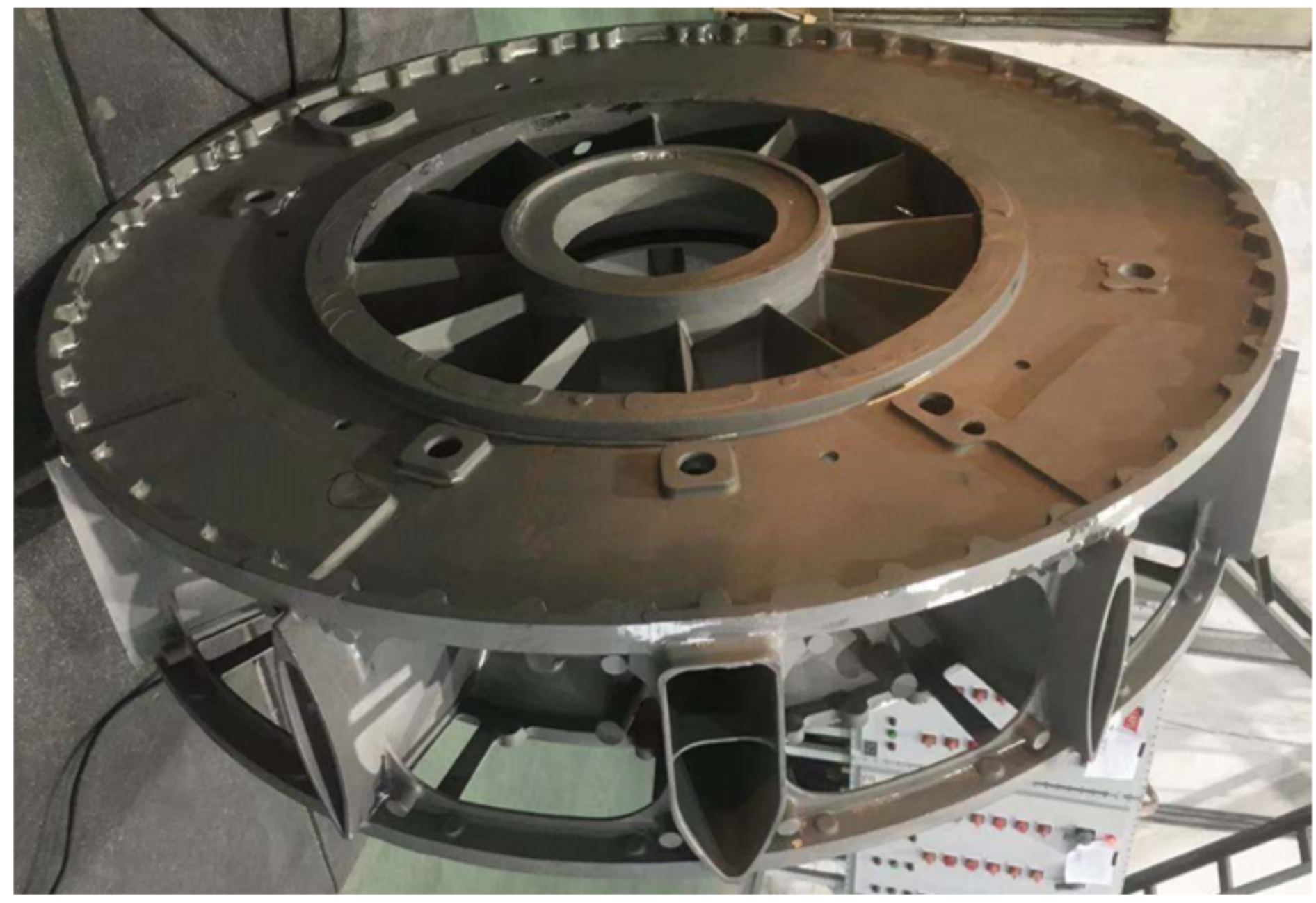

Figure 9

Final intermediate casing after cutting gating system 